\title{
Ecological contribution of Fenton process for generation of a ready-to-reuse dyeing and finishing effluent
}

\author{
Wafa Miled ${ }^{1,2}$ and Neji Ladhari ${ }^{2}$ \\ 'Department of Early Childhood, University College Taraba, Taif University, Saudi Arabia \\ ${ }^{2}$ Textile Engineering Laboratory LGTex, Height Institute of Technical Studies (ISET) of Ksar Hellal, AV Hadj Ali Soua, 5070, Ksar Hellal, \\ Monastir University, Tunisia
}

\begin{abstract}
In this study, real wastewater from a dyeing factory and previously treated by biological processes was decolorized by Fenton oxidation. Direct and reactive dyebaths and the related auxiliaries constituted the polluted effluents. A synthetic wastewater was also prepared in the same way in order to compare degradation performance. The study was performed with a systematic approach, searching optimum values of $\mathrm{H}_{2} \mathrm{O}_{2}$ and $\mathrm{FeSO}_{4}$ concentrations, $\mathrm{pH}$, temperature and the chemical structure of each tested dye. Depollution results showed that the oxidation behaviour of synthetic and real wastewaters was very similar, especially during the first stage where the breaking of chromophore groups allowed fast colour removal. However, it was found that higher ratios of $\left[\mathrm{H}_{2} \mathrm{O}_{2}\right] /\left[\mathrm{FeSO}_{4}\right]$ must be engaged in the case of real wastewaters. Results also showed that the catalytic oxidation yielded a fast and complete depollution at $\left[\mathrm{H}_{2} \mathrm{O}_{2}\right] /\left[\mathrm{FeSO}_{4}\right]=70, \mathrm{pH} 3$ and temperature $40^{\circ} \mathrm{C}$. For experiments with direct dye, colour and COD removals were, respectively, $90 \%$ and $87 \%$ in the case of real wastewater. Reactive real wastewater showed non-stable oxidation evolution due to the hydrolysed dyestuff and this led to $83 \%$ and $45 \%$ decolourization and COD removal, respectively. Better depollution results were noted for the synthetic wastewater experiments. This finding was related to the non-stable composition of the real wastewater and the unknown chemical and physical interferences between its compounds. After sedimentation, reuse of the treated wastewater for new dyeing experiments was also investigated. For this purpose, the whole process was run under complete recycling mode and the previously treated effluent was re-used as fresh dyebath. Results in terms of colour depth and fastness showed that dyeing performances were very similar, and an important opportunity is offered by reusing wastewater treated by Fenton oxidation process.
\end{abstract}

\section{INTRODUCTION}

The textile industry in Tunisia has great economic importance and the government has given it special attention (Kahia, 2017). A significant number of textile factories are currently operating in the country. Most of these factories are engaged in the process of dyeing and finishing (Kahia, 2017; Tounés et al., 2018). Although more than $60 \%$ of textile factories are linked to effluent treatment plants, the partially treated effluent is discharged into the nearby sea, rivers, lakes and streams. When discharge volume and effluent composition are considered, the Tunisian textile industry is the most polluting sector in the country (Kahia, 2017; Tounés et al., 2018). Such wastewater has a serious negative impact on groundwater and aquatic life (Carmen and Daniel, 2012). Problems are related to the high colour, high chemical oxygen demand, low biodegradability, fluctuating $\mathrm{pH}$ and high temperature of the discharged wastewater (Allegre et al., 2004; Banat et al., 1996; Carmen and Daniel, 2012; Miled et al., 2010). Aside from the waste containing a large amount of water, it also contains useful chemicals and auxiliaries, which are economically attractive.

On the other hand, the increasing cost of water and its wasteful consumption required a treatment process which must be integrated with in-plant water circuits rather than as a subsequent treatment. There are different wastewater treatment mechanisms which can be suitable for textile dye houses (Allegre et al., 2004; Banat et al., 1996; Bouatay et al., 2015; Kim et al., 2003; Miled et al., 2010). Waste management is commonly carried out using biological and physicochemical methods (Allegre et al., 2004; Banat et al., 1996; Miled et al., 2015; Sabur et al., 2012). However, many of the commercially used dyes are resistant to biodegradation (Banat et al., 1996; Carmen and Daniel, 2012; Ghoreishi and Haghighi, 2003; Miled et al., 2015; Sabur et al., 2012). Coagulationflocculation followed by sedimentation or adsorption is widely used, but is not promising due to the secondary pollution arising from the residual sludge. Aerobic biological treatments are the most widely employed in the Tunisian textile wastewater units but have low efficiency with synthetic dyes, which represent more than $80 \%$ of the annual consumption in theses factories (Kahia, 2017; Tounés et al., 2018). For theses dyes, biological process cannot be efficient due to the high resistance of synthetic dyes to biological degradation and the huge volume of the wastewater. Some attempts are being made to engage natural dyes, but lower efficiency was noted due to the low reproducibility of dyeing results (Samanta and Agarwal, 2009).

Considering the case of cotton factories, which are abundant in Tunisia, direct and reactive dyes are the most commonly used dyestuffs. Such dyes are anionic, with good solubility. They consume huge quantities of salts to ensure the exhausting step and have high chemical and photolytic stability (Nawaz and Ahsan, 2014; Selcuk, 2005). As a consequence, they will be present in high quantities

\section{CORRESPONDENCE \\ Wafa Miled}

\section{EMAIL}

w.miledbenltoufa@gmail.com

\section{DATES}

Received: 10 August 2018

Accepted: 12 December 2019

\section{KEYWORDS}

Fenton process

real wastewater colour removal cod removal reactive dye direct dye

\section{COPYRIGHT}

() The Author(s) Published under a Creative Commons Attribution 4.0 International Licence (CC BY 4.0) 
in natural water resources in the absence of adequate tertiary treatments (Allegre et al., 2004; Banat et al., 1997; Ganesan and Thanasekaran, 2011; Peralta-Hernández et al., 2008).

In order to discharge wastewaters that meet legislative requirements, innovative processes using bio-adsorbents, biogases or electrochemical techniques have been tested and applied in combined ways (Barrera-Díaz et al., 2003; Miled et al., 2010). Most of these methods can only transfer contaminants from one phase to the other leaving the problem essentially unsolved. In addition, such depollution systems do not include attractive opportunities of recycling since results of depollution are unsatisfactory. Treatment of effluents from reactive and direct dyes involves additional complications due to the high residual salinity, which makes reuse of treated wastewaters for irrigation, for example, impossible (Khatri et al., 2015; Selcuk, 2005). Natural-based technologies have also been proposed in order to reduce the impact of hazardous materials generated from industrial wastewaters. In this case, promising depollution results were noted (Panga Kiran Kumar et al. 2018). Free or low energy requirements and environmentally friendly technologies such as ozonation, membrane filtration, and adsorption have also been proposed and successfully implemented to treat textile effluents (Yusuf et al., 2018).

Recently, interest in chemical oxidative processes for textile wastewater treatment is increasing because these processes actually involve the degradation of the pollutant, although never complete (Eslami et al., 2013; Ledakowicz et al., 2001). A number of advanced oxidation processes are currently being evaluated for the destruction of dyes in effluents. The most discussed technologies for reuse are membrane bioreactors, electrochemical systems and denitrifying bio-filters (Ciardelli et al., 2000; Eslami et al., 2013; Ledakowicz et al., 2001). These systems were not easily accepted, due to drawbacks such as large area requirements, field operation problems and related costs. The Fenton process is one of the oldest advanced oxidation processes that has been used successfully for wastewater treatments, as it is comparatively low cost and uses easy to handle reagents (Kuo, 1992; Mansoorian et al., 2014; Martins, 1998; Meriç et al., 2004). The Fenton process allows for the production of highly active hydroxyl radicals resulting from the reaction of hydrogen peroxide with iron (II) ions. Undoubtedly the process efficiency can be improved and intensified because the oxidation of organic compounds by the hydroxyl radical generated in situ is much faster than classical oxidation compounds (Al-Kdasi et al., 2004; Martins, 1998; Palaniandy et al., 2014; Zaharia et al., 2009). The chemistry of the Fenton process is initiated after the generation of hydroxyl radicals as follows (Perkowski and Kos, 2002):

$$
\mathrm{H}_{2} \mathrm{O}_{2}+\mathrm{Fe}^{2+} \rightarrow \mathrm{Fe}^{3+}+\mathrm{OH}^{-}+\mathrm{OH}^{\cdot}
$$

The formed oxidizing and propagating agents initiate the decolorization and decomposition reactions of organics $(\mathrm{RH})$ :

$$
\begin{aligned}
& \mathrm{OH}^{\bullet}+\mathrm{RH} \rightarrow \mathrm{H}_{2} \mathrm{O}+\mathrm{R}^{\bullet} \\
& \mathrm{R}^{\bullet}+\mathrm{H}_{2} \mathrm{O}_{2} \rightarrow \mathrm{ROH}+\mathrm{OH}^{\bullet}
\end{aligned}
$$

$\mathrm{OH} \cdot$ radicals also decompose $\mathrm{H}_{2} \mathrm{O}_{2}$ producing $\mathrm{HO}_{2} \cdot$ radicals:

$$
\mathrm{OH}^{\bullet}+\mathrm{H}_{2} \mathrm{O}_{2} \rightarrow \mathrm{H}_{2} \mathrm{O}+\mathrm{HO}_{2} \cdot
$$

The kinetic chain can be stopped by reactions between radicals as follows:

$$
\begin{aligned}
& \mathrm{OH}^{\cdot}+\mathrm{OH}^{\cdot} \rightarrow \mathrm{H}_{2} \mathrm{O}_{2} \\
& \mathrm{Fe}^{2+}+\mathrm{HO}^{\cdot} \rightarrow \mathrm{Fe}^{3+}+\mathrm{HO}^{-} \\
& \mathrm{Fe}^{2+}+\mathrm{HO}_{2} \rightarrow \mathrm{Fe}^{3+}+\mathrm{HO}_{2}
\end{aligned}
$$

In this study, the use of the Fenton process was explored for the decolorization of real wastewaters from a cotton dyeing and finishing factory. The purpose was to investigate the effectiveness of the Fenton process for the decolorization of such wastewaters, having different complexity and chemical stability behaviours. Attempts are also being made to find an appropriate wastewater treatment for cotton dyeing factories that allows recycling and countering the negative impact of human activities on the environment. For this purpose, the real wastewater used was a mixture of either direct or reactive dyes with their related finishing reagents. Synthetic wastewaters were also prepared and investigated in this study. The goal was to compare the results of depollution of the industrial wastewater, for which real proportions and composition cannot be exactly defined, with the simulated wastewater with a known and well-defined composition. The investigation covered the determination of parameters affecting process efficiency in order to discover optimum values. The performance of the Fenton process was evaluated especially in terms of colour and COD removal, but also using many other pollution parameters such as suspended solids, biodegradability and turbidity. The resulting water quality was then investigated in dyeing experiments to evaluate its quality for re-use. Dyeing performances were evaluated and compared to those obtained with freshly prepared dyebaths.

\section{MATERIALS AND METHODS}

\section{Chemicals}

All chemicals employed in this study were of commercial grade. Reagent grade $\mathrm{H}_{2} \mathrm{O}_{2} 35 \%$ (Chimitex) was standardized using iodometric titration and used as purchased. Iron sulfate $\mathrm{FeSO}_{4} \cdot 7 \mathrm{H}_{2} \mathrm{O}$ was standardized just before Fenton experiments. $\mathrm{NaOH}$ and $\mathrm{H}_{2} \mathrm{SO}_{4}$ were also used for $\mathrm{pH}$ adjustments.

Commercial direct (azoic structure) and reactive dyes (vinyl sulfonic structure) and related auxiliaries (exhausting agent, Glauber's salt, sequestering agent and wetting agent) were of technical grade and were used as received without any purification in order to achieve similar preparation conditions for both synthetic and real wastewaters.

\section{Sample preparation}

The real wastewater was supplied from a dyeing and finishing Tunisian textile company located in Monastir Government. $20 \mathrm{~L}$ of the dyebath was collected from the dyeing machine prior to its discharge. Then, the collected wastewater was passed separately through a pilot-scale biological treatment apparatus. Biologically treated samples were preserved in the refrigerator at $4^{\circ} \mathrm{C}$ in accordance with standard methods (APHA/AWWA/ WPCF, 1975) before characterisation.

Synthetic wastewater was prepared in once-distilled water by using the same mixture of auxiliaries used in the industrial dyeing process. Synthetic wastewater was also collected after a dyeing process at laboratory scale in order to consider the exhaust rate of each chemical introduced in the dyebath. Both wastewaters were analysed. The related characteristics are shown in Table 1 . The chemical structure and main features of the investigated commercial dyestuff are detailed in Table 2.

\section{Fenton oxidation procedure}

Fenton oxidation experiments were carried out in a laboratoryscale batch reactor. In every assay, the reactor was filled with $500 \mathrm{~mL}$ of either synthetic or real wastewater. Then the iron dose was added under stirring and the $\mathrm{pH}$ of the initially basic sample was adjusted by adding sulfuric acid. In every case, the reaction was started by adding the dose of hydrogen peroxide. 
Table 1. Characterization of tested wastewaters

\begin{tabular}{|c|c|c|c|c|}
\hline \multirow{2}{*}{ Parameter } & \multicolumn{2}{|c|}{ Synthetic wastewater } & \multicolumn{2}{|c|}{ Real wastewater } \\
\hline & Direct dye & Reactive dye & Direct dye & Reactive dye \\
\hline Colour (at $\lambda \max$ ) & 3.55 (diluted 10 times) & 4.01 (diluted 10 times) & 2.01 (diluted 10 times) & 5.23 (diluted 10 times) \\
\hline $\operatorname{COD}\left(\mathrm{mg} \mathrm{O}_{2} / \mathrm{L}\right)$ & 995 & 1186 & 1230 & 1740 \\
\hline $\mathrm{BOD}\left(\mathrm{mg} \mathrm{O}_{2} / \mathrm{L}\right)$ & 374 & 295 & 620 & 450 \\
\hline Suspended matter (g/L) & 200 & 186 & 372 & 254 \\
\hline Turbidity (NTU) & 78 & 44 & 138 & 89 \\
\hline Conductivity (mS/cm) & 16.07 & 19.12 & 20.24 & 25.59 \\
\hline
\end{tabular}

Table 2. Main features of commercial dyestuffs

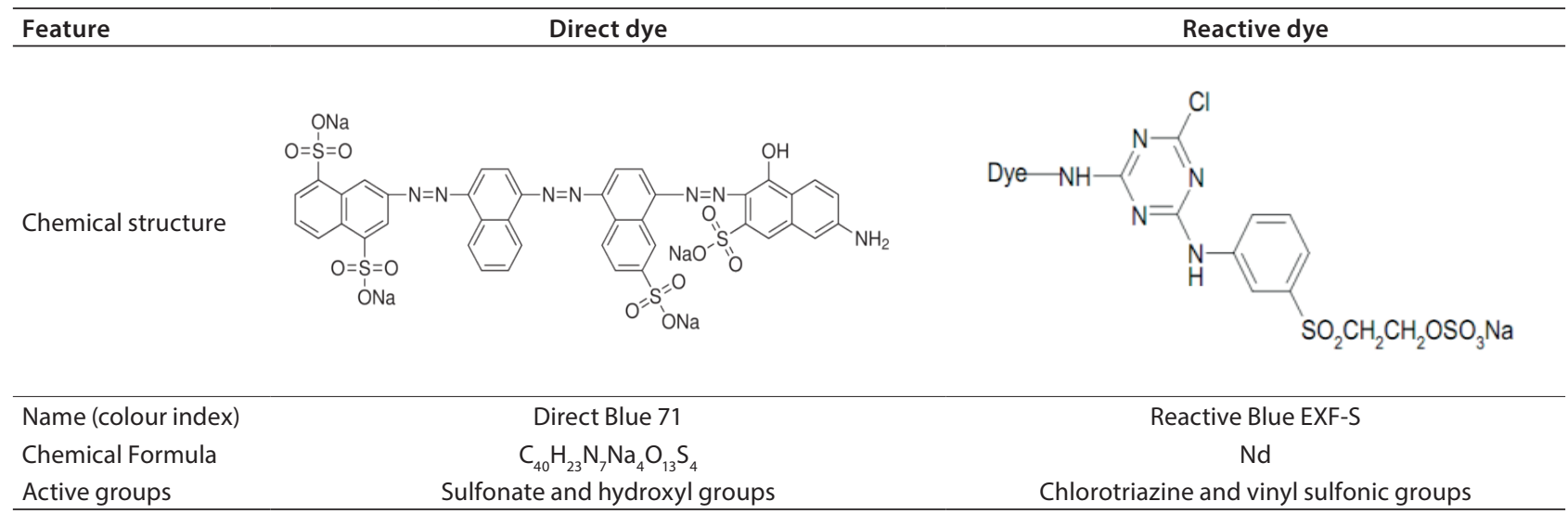

Several preliminary experiments were carried out to find the range of hydrogen peroxide and iron sulfate doses, time, temperature and $\mathrm{pH}$ needed to obtain better depollution results. After these experiments, the molar fraction of $\left[\mathrm{H}_{2} \mathrm{O}_{2}\right] /\left[\mathrm{FeSO}_{4}\right]$ was varied from 20 to 100 . The $\mathrm{pH}$ of the solution was measured with a calibrated $\mathrm{pH}$ meter of Jenway type and varied from 2 to 4.5 . Experiments were conducted on the dye solutions at $40^{\circ} \mathrm{C}, 60^{\circ} \mathrm{C}$ and $90^{\circ} \mathrm{C}$ temperatures. This range was chosen by considering the conditions in the dyeing and finishing industry (Carmen and Daniel, 2012). All experiments were done in triplicate. Laboratory experiments were repeated 5 times and statistical analysis confirmed the reproducibility of values.

\section{Textile support specifications}

For dyeing experiments, a commercially scoured and bleached cotton fabric (surface weight $180 \mathrm{~m}^{2}$, weft count: 25 and warp count 35) was supplied and used.

\section{Dyeing procedure}

The previously treated wastewater at optimal conditions was reused as dyebath after a sedimentation step. Dyeing experiments were conducted in batch mode. Scoured and bleached cotton fabric was introduced to the dye bath at a temperature below the dyebath exhaustion temperature. Electrolyte (sodium sulphate) and sequestrate agent were added to the dyebath to increase the exhaustion rate of the dye. The concentration of the electrolyte depended on the shade. For a medium shade (3\% owf), $50 \mathrm{~g} / \mathrm{L}$ of $\mathrm{Na}_{2} \mathrm{SO}_{4}$ was introduced in the case of reactive dye and $20 \mathrm{~g} / \mathrm{L}$ for direct dyes. For both tested dyes, the initial $\mathrm{pH}$ was adjusted to a value of 7.0. To ensure fixation of reactive dye, caustic soda was added to the dyebath after migration of the dye. Experimental conditions are detailed in Table 3.

At the end of the dyeing process, the dyebath was taken out of the machine and cooled under tap water. After rinsing, the dyed samples were also treated separately in a fixing/soaping process to provide better fastness properties. Other cotton samples were dyed with fresh water by maintaining the same experimental
Table 3. Dyeing experimental conditions

\begin{tabular}{lcc}
\hline \multirow{2}{*}{ Parameter } & \multicolumn{2}{c}{ Dye type } \\
\cline { 2 - 3 } & Direct dye & Reactive dye \\
\hline [Dye] & $3 \%$ o.w.f & $3 \%$ o.w.f \\
Sequestering agent & $2 \mathrm{~g} / \mathrm{L}$ & $2 \mathrm{~g} / \mathrm{L}$ \\
Wetting agent & $1 \mathrm{~g} / \mathrm{L}$ & $1 \mathrm{~g} / \mathrm{L}$ \\
MLR & $1.20($ defined by the dyeing apparatus.) \\
[Glauber's Salt] & $20 \mathrm{~g} / \mathrm{L}$ & $50 \mathrm{~g} / \mathrm{L}$ \\
pH & 7 & From 8 to 10.5 \\
Total duration & $60 \mathrm{~min}$ & $75 \mathrm{~min}$ \\
Temperature & $30-95^{\circ} \mathrm{C}$ & $30-50^{\circ} \mathrm{C}$ \\
\hline
\end{tabular}

conditions. These samples were considered as a reference for the colorimetric study.

\section{Analytical evaluation \\ Colour and chemical oxygen demand analyses}

The colour evolution was measured by evaluating the absorbance of wastewater before and after each treatment. Absorbance measurements were carried out with a UV-Visible spectrophotometer (Shimadzu UV-256) recording the spectra over the 190-900 nm range. A graph is obtained (visible) and the absorbance of the solution is taken at the wavelength corresponding to the absorbance peak.

Direct and reactive dyes with different absorbance peaks were present in the studied wastewaters. The maximum absorbance of the real wastewater is non-stable, so prior to each experiment UV-Vis spectra of dye solutions were plotted to establish their maximum.

The disappearance of the absorbance peaks of the treated solutions was monitored and the colour removal ratio was calculated as follows:

$$
\operatorname{abs}(\%)=\frac{\operatorname{abs}\left(\lambda_{\max }\right)_{i n i}-\operatorname{abs}\left(\lambda_{\max }\right)_{t}}{\operatorname{abs}\left(\lambda_{\max }\right)_{i n i}}
$$

where abs $\left(\lambda_{\max }\right)_{\text {ini }}$ is the initial average value of absorbency at $\lambda_{\max }$ of the concerned wastewater, abs $\left(\lambda_{\max }\right)_{t}$ is the value obtained at time $t$. 
Chemical oxygen demand tests were performed by oxidation with dichromate according to standard methods (APHA/ AWWA/WPCF, 1975) with a subsequent colorimetric determination using Hach DR 2000 photometer. The percentage of dye mineralization was evaluated by using the formula:

$$
\operatorname{COD}(\%)=\frac{\mathrm{COD}_{i}-\mathrm{COD}_{t}}{\mathrm{COD}_{i}} \times 100
$$

where $\mathrm{COD}_{\mathrm{i}}$ corresponds to the initial value and $\mathrm{COD}_{t}$ is the value obtained at time $t$.

\section{Dyed sample evaluation}

Results of the dyeing experiments were characterized by colour measurements in the form of colour strength $K / S$ and CIELab coordinates. Measurements were done with the help of a colorimeter SPECTRAFLASH 300 (Datacolor International, 1994) interfaced to a PC using D65 light source and viewing angle of $10^{\circ}$. The distance in colour space, $\Delta \mathrm{E}_{\mathrm{CMC}}$, represents the difference between results obtained by dyeing experiments with fresh wastewater and re-used dyebath. It is calculated using Eq. 10:

$$
\Delta E_{C M C}=\sqrt{\Delta L^{2}+\Delta a^{2}+\Delta b^{2}}
$$

where $\mathrm{L}^{*}$ corresponds to the brightness $(100=$ white; $0=$ black $)$; $\mathrm{a}^{*}$ to the red-green coordinate (positive sign $=$ red, negative sign $=$ green) and $\mathrm{b}^{\star}$ to the yellow-blue coordinate (positive sign $=$ yellow, negative sign $=$ blue).

The colour strength $(K / S)$ of the samples was determined by taking S1 as the reference (100\% colour strength). The following formula was used for the calculation:

$$
K / S=\frac{(1-R)^{2}}{2 R} \times 100
$$

Dyed samples were also evaluated for wash fastness (Sources: IS 764; 1979) and rubbing fastness (Source: IS 766; 1988).

\section{RESULTS AND DISCUSSION}

\section{Experimental conditions of Fenton oxidation process}

\section{Effect of $\left[\mathrm{H}_{2} \mathrm{O}_{2}\right] /\left[\mathrm{FeSO} \mathrm{O}_{4}\right]$ molar ratio}

Although the Fenton reaction has been widely studied, there is still no agreement on the ratio $\left[\mathrm{H}_{2} \mathrm{O}_{2}\right] /\left[\mathrm{FeSO}_{4}\right]$ that gives the best depollution levels (Al-Kdasi et al., 2004; Palaniandy et al., 2014). Many researchers have reported the use of different ratios of the two reactants (Meriç et al., 2004; Palaniandy et al., 2014 Wang, 2008). An excess of $\mathrm{H}_{2} \mathrm{O}_{2}$ or $\mathrm{FeSO}_{4}$ might be detrimental,

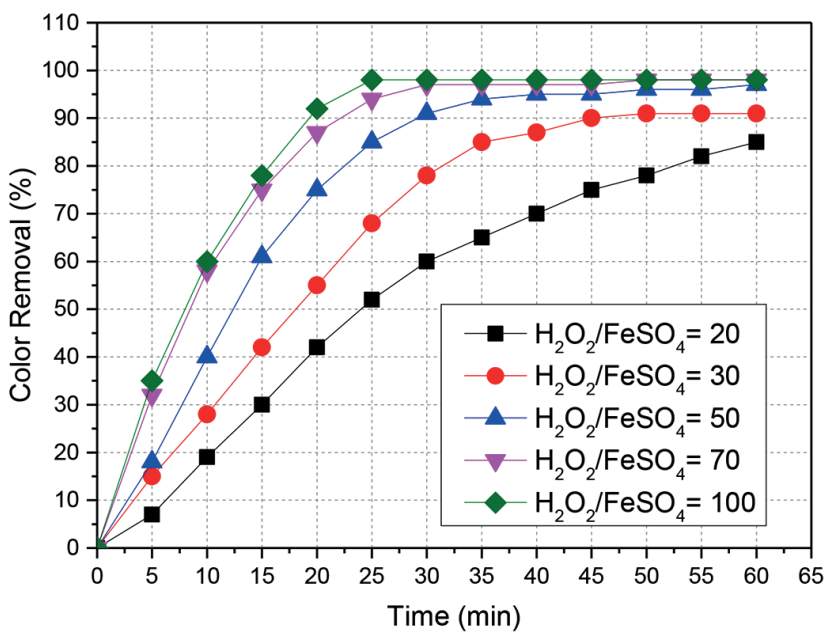

Figure 1. Effect of $\left[\mathrm{H}_{2} \mathrm{O}_{2}\right] /\left[\mathrm{FeSO}_{4}\right]$ ratio on decolorization of real wastewater (direct dye, temperature $40^{\circ} \mathrm{C}, \mathrm{pH} 3$ ) since these species can react with some of the intermediates like $\mathrm{OH}^{\cdot}$ responsible for the direct oxidation of the organic load. Such a reaction can lead to a decrease in process efficiency by consumption of the $\mathrm{OH}^{*}$. Some other side reactions can occur causing destabilization of $\mathrm{pH}$ values during experiments or the formation of iron (II) or (III) hydroxyl sludges (Benatti and Tavares, 2012).

Figures 1 and 2 contain data concerning experiments with $\left[\mathrm{H}_{2} \mathrm{O}_{2}\right] /\left[\mathrm{FeSO}_{4}\right]$ ratios varied from 20 to 100 . Experiments were carried out for $1 \mathrm{~h}$ at $40^{\circ} \mathrm{C}$ and $\mathrm{pH} 3$ for real wastewater.

From these figures, it becomes clear that increasing the $\left[\mathrm{H}_{2} \mathrm{O}_{2}\right] /$ $\left[\mathrm{FeSO}_{4}\right]$ ratio leads to larger colour removal, with no detrimental effects detected for ratios higher than 70 . Nevertheless, the small difference between the colour removal attained with 70 and 100 ratios indicates that improvements of reaction rate may not compensate for the large amounts of oxidant consumed (Miled et al., 2015).

Figure 1 also shows that during the first 25 min the reaction proceeds at a faster rate. With ratios of $\left[\mathrm{H}_{2} \mathrm{O}_{2}\right] /\left[\mathrm{FeSO}_{4}\right]$ higher than 50, the decolorization kinetic was slightly higher than the decolorization levels obtained with lower ratios. This behaviour is not maintained for higher durations. This can be explained by taking into account that the Fenton reaction, which is completed after a few minutes, benefits immediately from larger $\left[\mathrm{H}_{2} \mathrm{O}_{2}\right] /$ $\left[\mathrm{FeSO}_{4}\right]$ ratios, while for lower ratios, the Fenton process needs more time to manifest, and its oxidation effect appears only for longer reaction times.

For the same experiments, we noted also that the best elimination of chemical oxygen demand was obtained for $\left[\mathrm{H}_{2} \mathrm{O}_{2}\right] /\left[\mathrm{FeSO}_{4}\right]$ ratios higher than 50 for which we noted coherent and identical evolution.

Figure 3 compares the wastewater quality after Fenton oxidation for real and synthetic wastewaters contaminated by direct dye. Results show similar behaviour of colour removal and COD abatement for real and synthetic wastewaters by varying the molar ratio $\left[\mathrm{H}_{2} \mathrm{O}_{2}\right] /\left[\mathrm{FeSO}_{4}\right]$. The evolution of colour removal and decomposition of the synthetic wastewater was faster and more regular. In contrast, the evolution mentioned with real wastewater showed more fluctuations. Such wastewater has non-stable composition or concentration of pollutants. It should be pointed out that organic dyes used in this study have poly-aromatic structures with $-\mathrm{N}=\mathrm{N}-$ and $-\mathrm{C}=\mathrm{C}-$ type double bonds in their chromophore groups. These dyes will readily react with $\mathrm{OH}^{\bullet}$ that

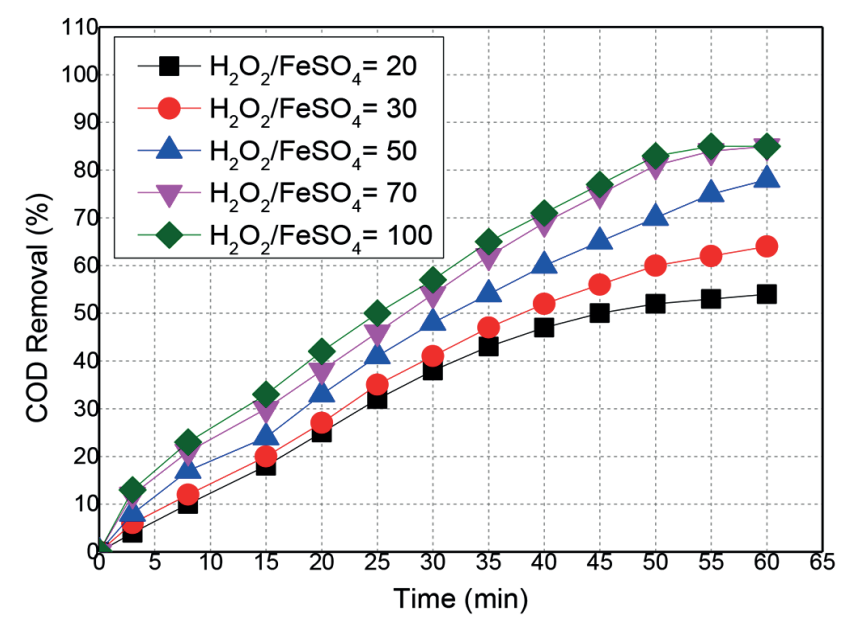

Figure 2. Effect of $\left[\mathrm{H}_{2} \mathrm{O}_{2}\right] /\left[\mathrm{FeSO}_{4}\right]$ ratio on $\mathrm{COD}$ removal of real wastewater (direct dye, temperature $40^{\circ} \mathrm{C}, \mathrm{pH} 3$ ) 


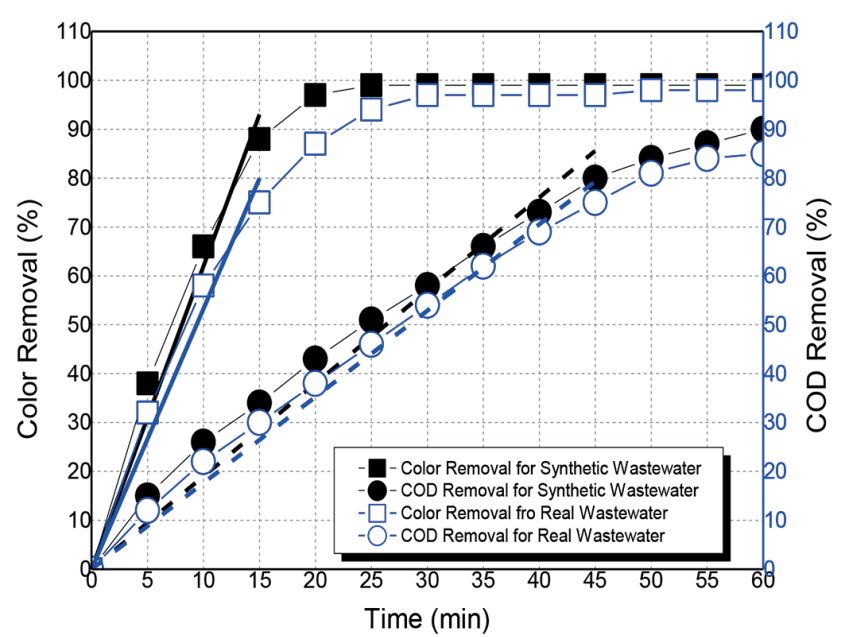

Figure 3. Comparison of colour and $\mathrm{COD}$ removal for synthetic and real wastewater (direct dye, temperature $40^{\circ} \mathrm{C}, \mathrm{pH} 3,\left[\mathrm{H}_{2} \mathrm{O}_{2}\right] /\left[\mathrm{FeSO}_{4}\right]=70$ )

is the major oxidizing agent in an acidic $\mathrm{pH}$ medium. Considering the presence of $\mathrm{OH}^{*}$ scavengers/competitors (anionic surfactant, antifoam, sequestering agent, equalizer, dispersing agent) in the real wastewater formulation, significant difference and variability should be expected between the reaction evolutions through all studied ratios (Miled et al., 2015; Zahria et al., 2009). This variability could have more influence before biological treatment. Such treatment has great dependence on wastewater composition and interferences between chemicals may cause irregular evolution of the decomposition behaviour. For this study, we recall that the collected wastewaters were previously passed through an aerobic degradation, and the Fenton process was used as a tertiary treatment. Direct dyes are known to be recalcitrant compounds and have low biodegradability (due to their transformation to aromatic amines after oxidation); all oxidation experiments with hydroxyl radicals were more regular and homogenous than in the case of reactive dye oxidation. The irregular decomposition noted with reactive dyes was attributed to the aqueous instability of these dyes. All these findings were in agreement with previous works (Meriç et al., 2004; Siddiqua et al., 2017; Sun et al., 2009).

Results of decolorization and decomposition with reactive dye are presented in Fig. 4. From the figure, it is evident that the wastewater composition has a large influence on the reaction evolution behaviour. For the first $15 \mathrm{~min}$, the same decomposition behaviour was noted for real and synthetic wastewaters. At this stage, dye molecules were degraded to smaller compounds, more difficult to degrade (Miled et al., 2015). This explains the slower decomposition for longer durations. The irregular decolorization behaviour noted with real wastewater was attributed to the spontaneous hydrolysis phenomenon. In fact, reactive dyes are not degraded by conventional aerobic sewage treatment plants as they are resistant to biological oxidative degradation (Gottlieb et al., 2003). We noted this with the collected real wastewater that still contains a higher amount of hydrolysed dye than the synthetic wastewater collected directly after laboratory dyeing experiments and biological decomposition treatment.

\section{Effect of $p H$}

The tested real wastewater has a wide range of initial $\mathrm{pH}$ values, which can reach 11 or even 12 . The solution $\mathrm{pH}$ is an important operating parameter affecting removal efficiency in AOP (Al-Kdasi et al., 2004). It directly affects the mechanism of oxidation of dye because a change in $\mathrm{pH}$ of the solution involves a variation of the concentration of $\mathrm{Fe}^{2+}$. Therefore, the rate of

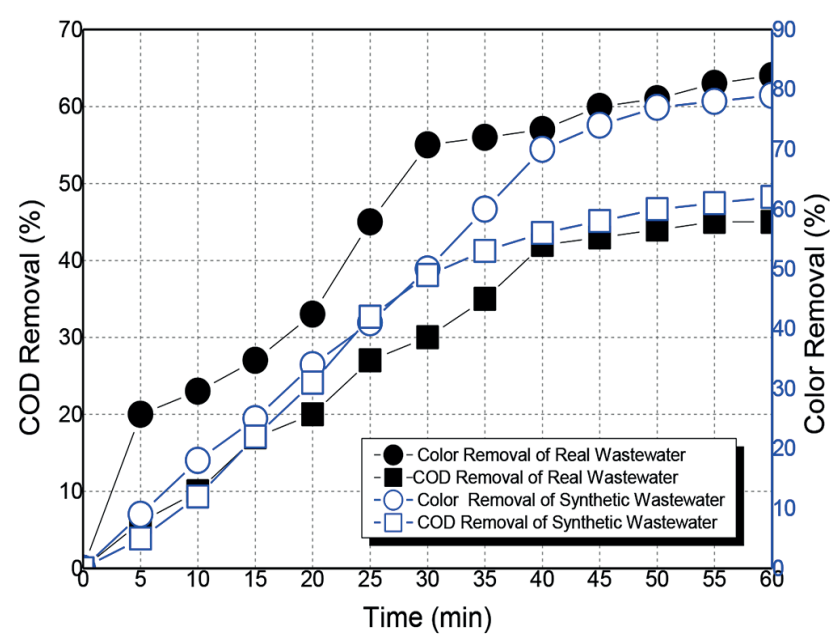

Figure 4. Comparison of colour and $\mathrm{COD}$ removals for synthetic and real wastewater (reactive dye, temperature $40^{\circ} \mathrm{C}, \mathrm{pH} 3,\left[\mathrm{H}_{2} \mathrm{O}_{2}\right] /\left[\mathrm{FeSO}_{4}\right]=70$ )

production of $\mathrm{OH}^{\cdot}$ radicals responsible for the oxidation of dyes will be restricted (Ertugay and Acar, 2013; Palaniandy et al., 2014; Sun et al., 2009). Thus, the decomposition reaction of $\mathrm{H}_{2} \mathrm{O}_{2}$ was found to be catalysed most efficiently by $\mathrm{Fe}^{2+}$ ions in water solutions with a $\mathrm{pH}$ value between 2 and 3 . In order to determine the optimal $\mathrm{pH}$, colour and COD removal were investigated in a larger range of $\mathrm{pH}$ values.

Figures 5 and 6 demonstrate that decolorization with Fenton's reagent in the cited conditions proceeded faster with a $\mathrm{pH}$ value of about 3, which is in accordance with the literature. Kuo (1992) observed $93 \%$ of decolorization of dye in $30 \mathrm{~min}$. Meric et al. (2004)Reactive Black 5 (RB5 showed that more than 99\% of colour removal was possible in the $\mathrm{pH}$ range of 3-3.5 for a synthetic wastewater containing only the dye. In our case, the real wastewater was a mixture of chemicals and some competitive side reactions must be taken into account. Colour removal of the real wastewater reached more than $80 \%$ after $45 \mathrm{~min}$.

At a lower $\mathrm{pH}$, there is an association of dye anions with positively charged Glauber's salt cations. Dye anions become electrostatically bonded to positively charged salt and enhance the attraction of the in-situ formed hydroxyl radical which makes the oxidation reaction faster. For $\mathrm{pH}$ values higher than 3 , a reverse reaction may occur. In fact, aqueous solutions of direct dyes have neutral behaviour. Direct dyes have symmetrical, flat and long molecular structures. This makes the aggregation of molecules possible. In order to ensure better solubility of direct dye before its use, a basic solution must be introduced at first. Higher $\mathrm{pH}$ causes swelling of the dyestuff and desegregation of molecules. A basic solution such as caustic soda reacts with hydroxyl groups of the dyestuff which creates new hydrogen bounds. The swelled dyestuff becomes slightly stronger and consequently more resistant to oxidation than dyes treated at acidic $\mathrm{pH}$ values. For $\mathrm{pH} 2$, the oxidation was clearly faster than the reaction at $\mathrm{pH} 4$. Dyes used in cotton processing actually become weaker in very acidic mediums and this improves the whole oxidation reaction, especially for the first 20 minutes. In addition, anions arising from the acid dissolution can scavenge the free radicals, based on Eq. 8. After the addition of sulfuric acid, the anions (X-), $\mathrm{X} \bullet$ (anion radical) are produced which have lower redox potential compared to sulfate and hydroxyl radicals (Zazouli et al., 2017):

$$
\mathrm{SO}^{*-} \text { or } \mathrm{HO}^{\bullet}+\mathrm{X}^{-} \rightarrow \mathrm{SO}_{4}^{2-} \text { or } \mathrm{HO}^{-}+\mathrm{X}^{\bullet}
$$

Figures 5 and 6 illustrate that the optimum $\mathrm{pH}$ varies over a small range. For the COD parameter, its variation as a function of time and $\mathrm{pH}$ was quite different. For $\mathrm{pH}$ equal to 2 there was 


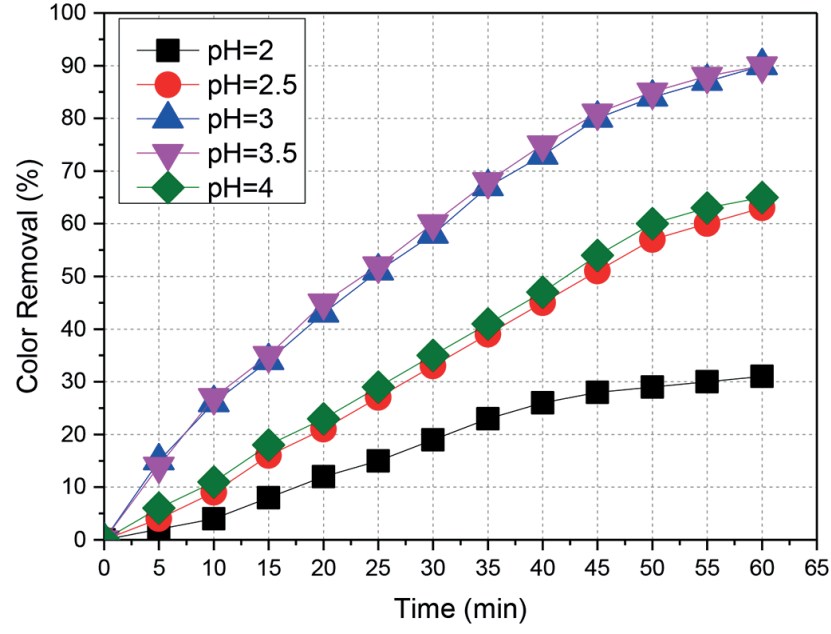

Figure 5. Effect of $\mathrm{pH}$ on colour removal of real wastewater (direct dye, temperature $40^{\circ} \mathrm{C},\left[\mathrm{H}_{2} \mathrm{O}_{2}\right] /\left[\mathrm{FeSO}_{4}\right]=70$ )

an almost linear evolution of COD removal but with insufficient depollution results. With $\mathrm{pH}$ values higher than 2.5 , especially when $\mathrm{pH}$ was $3-3.5$, the COD removal from real wastewater was better. For higher $\mathrm{pH}$ values, the precipitation phenomenon will be noted. This will cause inhibition of the Fenton process by the scavenger-formed ions. At optimum $\mathrm{pH}, \mathrm{COD}$ removal was $87 \%$.

\section{Effect of temperature}

Temperature is a key parameter that has to be taken into account, especially for those applications where colour and COD removal levels can be increased by varying temperature. It is important to note that, in comparison to most industrial wastewaters, the temperature of textile effluents undergoes large fluctuations (Carmen and Daniel, 2012). During the dyeing process, dye bath and rinse water temperatures of up to $90^{\circ} \mathrm{C}$ are normally encountered. For the finishing process, lower temperatures are used (about $40^{\circ} \mathrm{C}$ ). After conventional aerobic treatment, a temperature of $50^{\circ} \mathrm{C}$ should also be expected. In this section, Fenton process was tested in optimal conditions of $\mathrm{pH}$ and $\left[\mathrm{H}_{2} \mathrm{O}_{2}\right] /\left[\mathrm{FeSO}_{4}\right]$ molar ratio at 3 temperatures: $40^{\circ} \mathrm{C}, 60^{\circ} \mathrm{C}$ and $90^{\circ} \mathrm{C}$. Results are detailed in Figs 7 and 8 .

As seen from Figs 7 and 8, optimum temperature for a Fenton process is $40^{\circ} \mathrm{C}$, at which $87 \% \mathrm{COD}$ and $90 \%$ colour removal were obtained for the real wastewater contaminated with direct dye. In the case of higher temperatures of up to $60^{\circ} \mathrm{C}$, and

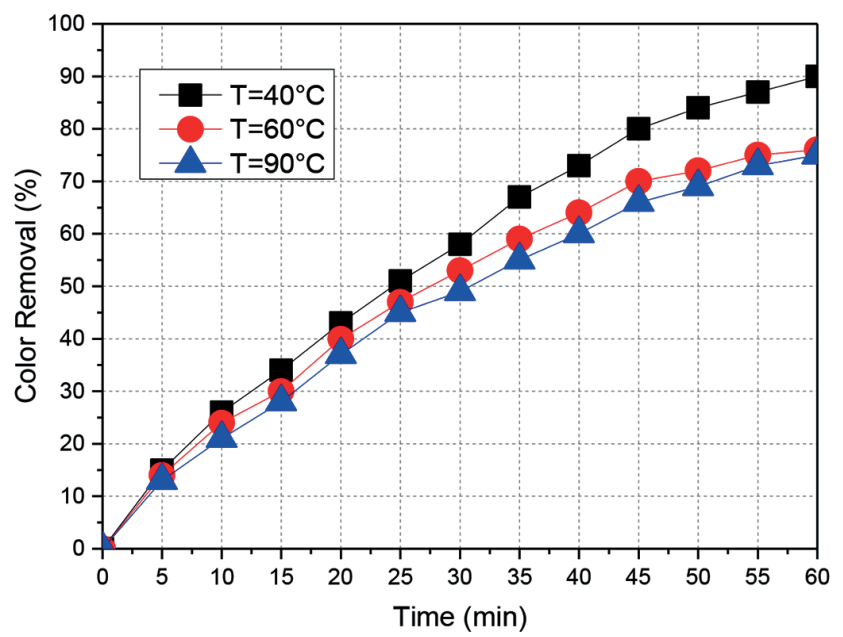

Figure 7. Colour removal by Fenton process of the real wastewater in $\mathrm{pH} 3,\left[\mathrm{H}_{2} \mathrm{O}_{2}\right] /\left[\mathrm{FeSO}_{4}\right]=70$ at $40^{\circ} \mathrm{C}, 60^{\circ} \mathrm{C}$ and $90^{\circ} \mathrm{C}$, direct dye

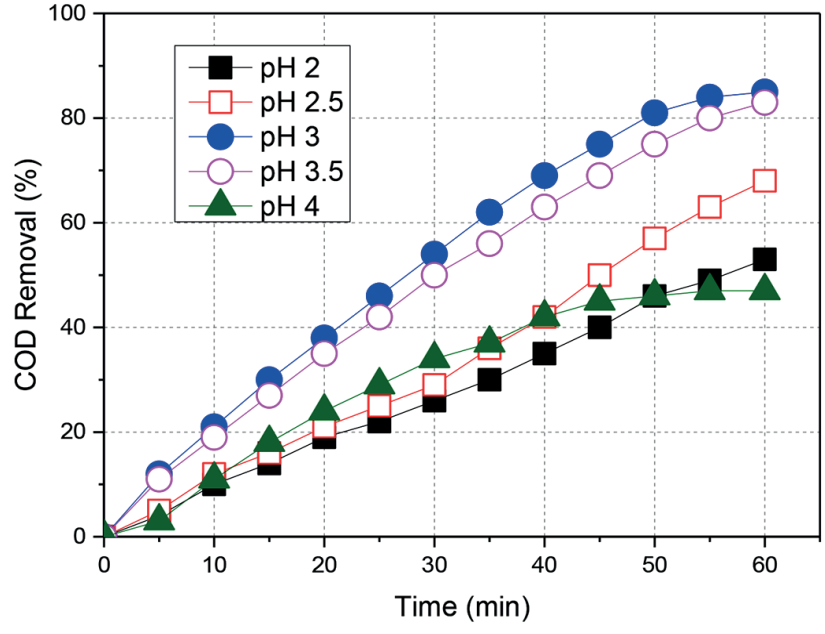

Figure 6. Effect of $\mathrm{pH}$ on $\mathrm{COD}$ removal of real wastewater (direct dye, temperature $40^{\circ} \mathrm{C},\left[\mathrm{H}_{2} \mathrm{O}_{2}\right] /\left[\mathrm{FeSO}_{4}\right]=70$ )

higher $\left[\mathrm{H}_{2} \mathrm{O}_{2}\right] /\left[\mathrm{FeSO}_{4}\right]$ molar ratios, COD removal was affected negatively. This can be explained by the destabilization of flocs resulting in increased ferrous ions that scavenged $\mathrm{OH}$ radicals during Fenton reactions (Al-Kdasi et al., 2004; Benitez et al., 2001; Peralta-Hernández et al., 2008). Higher temperatures were also tested and results confirmed the hypothesis of floc destabilization and the disturbance of the sedimentation process, thus resulting in the slightly slower colour and COD removals as shown in Figs 7 and 8. The same behaviour was noted with synthetic wastewater.

In addition, it was observed that the application of Fenton's reagent in the destruction of organic compounds at high temperature and $\mathrm{pH}$ generated a dark green/brown slurry phase. The sludge formed is mainly constituted by heavy metals $\mathrm{Fe}(\mathrm{III}) / \mathrm{Fe}(\mathrm{II})$-iron, with the formation of large amount of suspended solids (Benitez et al., 2001). Therefore, the overall result of the waste chemicals' treatment with Fenton's reagent is the production of an aqueous solution with a substantially lower total carbonaceous load. However, the treated liquor still presented levels of metals and suspended solids that were too high to meet discharge standards. Thus, Fenton's reagent cannot be applied as a stand-alone treatment option, but it can be used in combination with other techniques (Mansoorian et al., 2014). In our case, the oxidized wastewater was supported by a flocculation/sedimentation step.

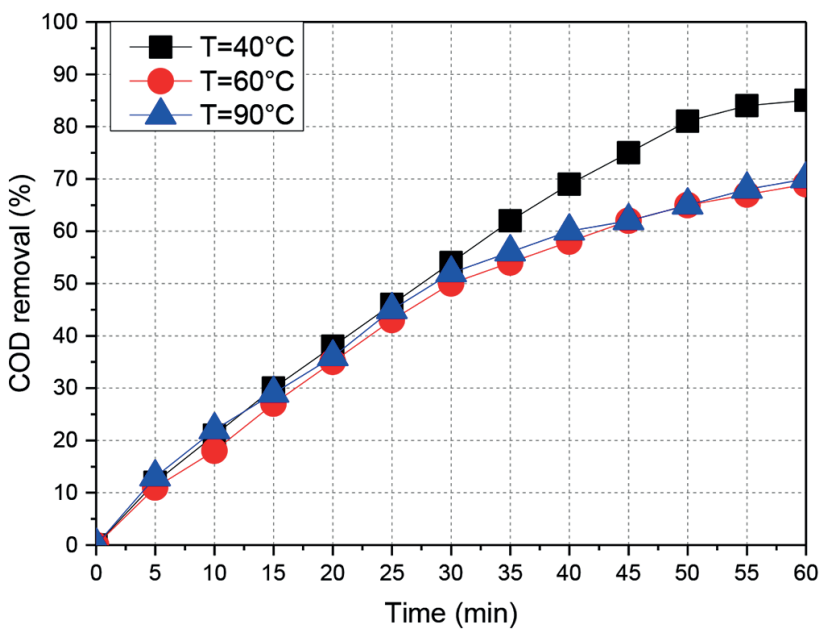

Figure 8. COD Removal by Fenton process of the real wastewater in $\mathrm{pH} 3,\left[\mathrm{H}_{2} \mathrm{O}_{2}\right] /\left[\mathrm{FeSO}_{4}\right]=70$ at $40^{\circ} \mathrm{C}, 60^{\circ} \mathrm{C}$ and $90^{\circ} \mathrm{C}$, direct dye 


\section{Effect of Fenton oxidation on typical pollution parameter reduction}

Table 4 summarizes the evolution of pollution levels of tested wastewaters before Fenton process application, after oxidation and finally after sedimentation.

The removal efficiency for the colour, chemical oxygen demand and biological oxygen demand after sedimentation was higher than $90 \%$ for direct dye experiments. Also, reactive dye experiments gave satisfactory results and depollution was noted to be higher than $80 \%$. This was not the case with the BOD parameter which showed a better decrease with direct dyes. All used wastewater passed through biological treatment before Fenton oxidation. The azoic chromophores of direct dye were better assimilated by the microorganisms used in the aerobic treatment. This led to smaller compounds that were then oxidized by hydroxyl radicals. As a consequence of this, removal was highly efficient. Reactive dye showed higher resistance to aerobic degradation due to its more complex chemical composition.

Turbidity and suspended solids were slightly reduced. Otherwise, Fenton oxidation leads to a mineralisation of organic compounds, so the final conductivity may be higher after total mineralisation. Through sedimentation, a small amount of the formed salts could be precipitated, which reduced the contribution of these salts to the increase in conductivity. For the reactive dye wastewater, less encouraging results were obtained, especially in terms of removal of COD and suspended materials. We related this to the hydrolysis phenomenon, which makes dye less reactive and more stable in aqueous solution.

\section{Reuse experiments}

Experimental results showed that chemical attack of the chromophores by the Fenton process led to better effluent quality. In fact, hydroxyl radicals generated by oxidation ensured the breaking of the chromophore's groups, which led to more stable decolorization results and probably created by-products that presented less problems for further dyeing experiments. After sedimentation of the treated wastewater, there was a significant decrease in all pollution parameters of the supernatant. As shown in Fig. 9, the sedimentation step after Fenton oxidation is obligatory since it ensures the elimination of a large part of the produced sludges at the end of the process.

The remaining wastewater was used to feed an industrial dyeing apparatus as shown in Fig. 10 (left). For this purpose, direct and reactive dyes and a cotton sample were employed as described in Tables 2 and 3. Dyeing results are also presented in Fig. 10. The CIELAB coordinates were analysed to understand the relation of those parameters with the tone of a target shade. The colour coordinates were also compared with standard dyeing results following the conditions cited in Table 3. Values of K/S and CIELab coordinates of dyeing experiments with reused and fresh water are given in Table 5.

For all experiments, $L^{\star}$ was found to be lower with fresh water, which indicates that samples dyed with fresh water were darker. More negative $a^{\star}$ values mean that the shade is greenish and the opposite of red. Negative $b^{\star}$ is related to the shade of the selected dyes which are blue.

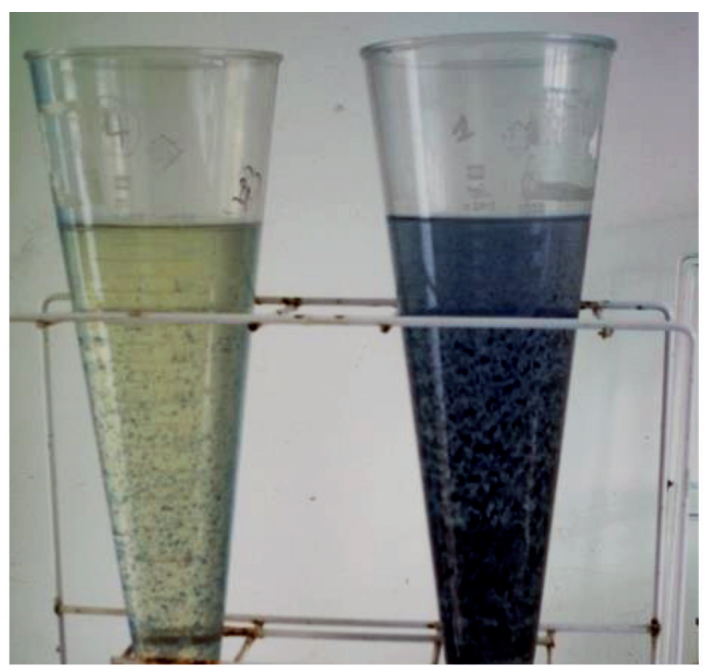

Figure 9. Real wastewater treated by Fenton process (left), by biological treatment (right) at the beginning of the sedimentation stage

Table 4. Characteristics of tested wastewaters before treatment, after Fenton process oxidation and after sedimentation

\begin{tabular}{|c|c|c|c|c|c|c|c|c|}
\hline \multirow{2}{*}{$\begin{array}{l}\text { Depollution } \\
\text { Parameter }\end{array}$} & \multicolumn{2}{|c|}{$\begin{array}{c}\text { Synthetic wastewater } \\
\text { of direct dye }\end{array}$} & \multicolumn{2}{|c|}{$\begin{array}{l}\text { Real wastewater } \\
\text { of direct dye }\end{array}$} & \multicolumn{2}{|c|}{$\begin{array}{c}\text { Synthetic wastewater } \\
\text { of reactive dye }\end{array}$} & \multicolumn{2}{|c|}{$\begin{array}{l}\text { Real wastewater } \\
\text { of reactive dye }\end{array}$} \\
\hline & $\begin{array}{c}\text { After } \\
\text { Fenton } \\
\text { oxidation }\end{array}$ & $\begin{array}{c}\text { After } \\
\text { sedimentation }\end{array}$ & $\begin{array}{c}\text { After } \\
\text { Fenton } \\
\text { oxidation } \\
\end{array}$ & $\begin{array}{c}\text { After } \\
\text { sedimentation }\end{array}$ & $\begin{array}{c}\text { After } \\
\text { Fenton } \\
\text { oxidation }\end{array}$ & $\begin{array}{c}\text { After } \\
\text { sedimentation }\end{array}$ & $\begin{array}{c}\text { After } \\
\text { Fenton } \\
\text { oxidation }\end{array}$ & $\begin{array}{c}\text { After } \\
\text { sedimentation }\end{array}$ \\
\hline Decolorization & $98 \%$ & $99 \%$ & $90 \%$ & $95 \%$ & $97 \%$ & $98 \%$ & $83 \%$ & $83 \%$ \\
\hline COD removal & $90 \%$ & $92 \%$ & $87 \%$ & $89 \%$ & $48 \%$ & $49 \%$ & $45 \%$ & $45 \%$ \\
\hline BOD removal & $92 \%$ & $95 \%$ & $90 \%$ & $92 \%$ & $65 \%$ & $67 \%$ & $53 \%$ & $54 \%$ \\
\hline $\begin{array}{l}\text { Suspended } \\
\text { atter reduction }\end{array}$ & $10 \%$ & $19 \%$ & $12 \%$ & $43 \%$ & $8 \%$ & $12 \%$ & $5 \%$ & $9 \%$ \\
\hline $\begin{array}{l}\text { Conductivity } \\
\text { evolution }\end{array}$ & $+52 \%$ & $+26 \%$ & $+45 \%$ & $+23 \%$ & $+13 \%$ & $+8 \%$ & $+15 \%$ & $+13 \%$ \\
\hline
\end{tabular}

Table 5. Colour yield and CIELab coordinates for the whole dyeing experiments with direct dye and reactive dye

\begin{tabular}{|c|c|c|c|c|c|c|}
\hline \multirow{2}{*}{ Samples dyed with /S } & & \multicolumn{5}{|c|}{ Colour coordinates } \\
\hline & & $L$ & $A$ & B & $\Delta E$ & \\
\hline \multirow{3}{*}{ Experiments with direct dye } & Fresh water added & 6.3262 & 40.52 & -2.66 & -21.13 & --- \\
\hline & Synthetic wastewater & 3.9874 & 45.23 & -3.72 & -22.76 & 5.09 \\
\hline & Real wastewater & 4.35231 & 43.11 & -4.22 & -21.89 & 3.11 \\
\hline \multirow{3}{*}{ Experiments with reactive dye } & Fresh water added & 4.4362 & 47.11 & -1.98 & -18.34 & --- \\
\hline & Synthetic wastewater & 4.0021 & 51.45 & -3.77 & -19.55 & 4.84 \\
\hline & Real wastewater & 3.7549 & 51.15 & -4.02 & -17.34 & 4.16 \\
\hline
\end{tabular}



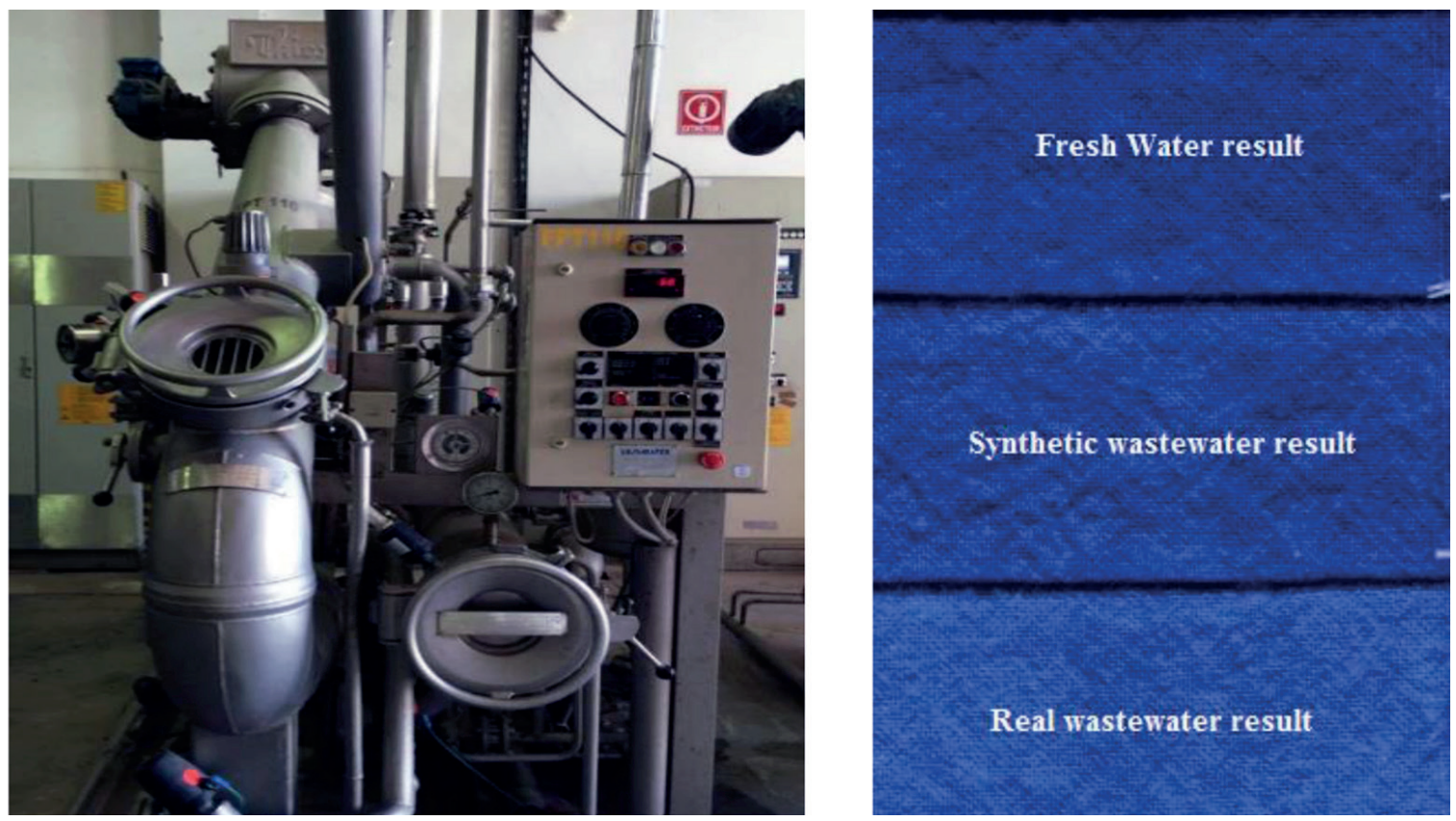

Figure 10. Dyeing apparatus (at left) and dyeing aspect with fresh water, synthetic and real wastewaters (at right)

When the shade becomes darker, it means that there is more opportunity for the dye to react with fibre, due to the presence of more reactive and available sites and/or less competitive species. The colour strength values K/S in Table 5 also support this reasoning. For reactive dye experiments, we noted the same evolution. The coordinate $a^{\star}$ was clearly more negative for all reuse experiments. The greenish shade can be related to the dark green/brown sludge formed after Fenton oxidation. According to Eq. 10, such variation influences the colour coordinate $a$ which causes the resulting colour space $\Delta E$ to be high.

In addition, the colour depth appears to increase with an increase in conductivity. The reused real wastewater had higher initial conductivity and allowed for better colour depth. The conductivity values mentioned in Table 5 show that real wastewater has the highest salinity after Fenton treatment which indicates that organic pollutants were mineralized. However, a better level of mineralization was noted with the synthetic wastewater, for which the completely mineralized fraction of organic compounds was $>55 \%$.

The variation of the CIELab coordinates makes clear that the colour depth and shade did not show strong dependence on the residual composition of the treated wastewater, although the overall result shows globally marginal improvement in colour coordinates of samples dyed with fresh water. After that, additional dyeing experiments were engaged on a dyeing apparatus with $10-\mathrm{kg}$ capacity. Experimental results were also very encouraging but are still under examination and need supplementary approvals, especially for darker shades.

All of the dyed samples were finally tested for washing fastness, wet and dry rubbing fastness. Results are shown in Table 6 .

All the results appeared to be equivalent to those for the samples dyed in fresh water and the reused synthetic wastewater. For the reused real wastewater, fastness to wet rubbing was slightly lower relative to the other results, although the dye uptake was better. This can be related to the dominance of more stable ionic bonds in synthetic wastewater. In fact, the affinity to direct dye was higher for samples dyed with the reused real wastewater, due to the residual higher conductivity level after Fenton mineralization of pollutants. However, linkages formed in the reused synthetic wastewater were better. Actually, in the dyeing process, direct dyes form hydrogen-bonds with the hydroxyl groups of cotton fibres. These bonds seem to be interfered with by by-products that the real wastewater may contain after Fenton oxidation (Liu et al., 2010). The colorimetric and fastness results for the tested dyes confirms that the reused wastewater can be an alternative water source which can reduce the demand for fresh water.

\section{CONCLUSIONS}

This study verifies the effectiveness of hydroxyl radicals generated from a catalytic oxidation process in treating textile wastewater. The treated effluent was subjected to further reuse. Synthetic and real wastewaters were tested and evaluated in terms of treatment and reuse efficiency. The results of this study can be summarized as follows:

Optimum conditions of Fenton oxidation were found to be $\mathrm{pH}=3$, temperature $=40^{\circ} \mathrm{C}$ and $\left[\mathrm{H}_{2} \mathrm{O}_{2}\right] /\left[\mathrm{FeSO}_{4}\right]= \pm 70$ for both synthetic and real wastewaters. For direct dye assays, pilot-scale experiments showed that colour and COD removals were, respectively, $90 \%$ and $87 \%$ in the real wastewater case, compared to $98 \%$ and $90 \%$ of colour and COD removals for the synthetic wastewater. Reactive real wastewater showed nonstable oxidation evolution due to the hydrolysation phenomenon which caused a more difficult decomposition process. Better depollution results were also noted for high $\left[\mathrm{H}_{2} \mathrm{O}_{2}\right] /\left[\mathrm{FeSO}_{4}\right]$ and acidic medium. In these conditions, $60 \mathrm{~min}$ of oxidation were

Table 6. Colour yield comparison of fastness properties of dyed samples

\begin{tabular}{lccc}
\hline \multirow{2}{*}{ Samples dyed with } & $\begin{array}{c}\text { Washing } \\
\text { fastness }\end{array}$ & \multicolumn{2}{c}{ Rubbing fastness } \\
\cline { 2 - 4 } & Direct dye results & Dry \\
\hline Fresh water & 4 & 3 & $3-4$ \\
Synthetic wastewater & 4 & $3-4$ & $3-4$ \\
Real wastewater & 4 & 2 & 3 \\
\hline & Reactive dye results & \\
Fresh water & 5 & $4 / 5$ & 5 \\
Synthetic wastewater & 4 & $4 / 5$ & $4 / 5$ \\
Real wastewater & 4 & 4 & 4 \\
\hline
\end{tabular}


necessary to reach $83 \%$ and $45 \%$ of decolorization and COD removal, respectively.

During oxidation of synthetic wastewater, known pollutants were decomposed more easily to smaller molecules, which were difficult to oxidize further. The whole degradation process occurred under more stable conditions since chemical interactions between by-products were avoided.

After Fenton oxidation followed by a sedimentation step, wastewater was collected and tested for reuse. The colorimetric and fastness results confirmed the feasibility of wastewater reuse. The proposed 'zero liquid discharge process' was successfully implemented with the pilot-scale apparatus and dyeing results on medium shades were also confirmed.

For darker shades, dyeing parameters should be selected in such a way that they can result in better colour strength. The process integrated recycling of dyeing effluents and could achieve obvious advantages for the investigated factory.

\section{REFERENCES}

AL-KDASI A, IDRIS A, SAED K and CHUAH T (2004) Review: Treatment of textile wastewater by advanced oxidation processes. Global Nest: The Int. J. 6 (3) 222-230.

APHA/AWWA/WPCF (American Public Health Association, American Water Works Association, Water Pollution Control Federation) (1975) Standard Methods for the Examination of Water and Wastewater (14 $4^{\text {th }}$ edn). APHA, Washington DC.

AYRTON M (1998) Advanced oxidation processes applied to effluent streams from an agrochemical industry. Pure Appl. Chem. 70 22712279. https://doi.org/10.1351/pac199870122271

BANAT I, NIGAM P, SINGH D and MARCHANT R (1997) Review: Microbial decolorization of textile-dye-containing effluents. Bioresour. Technol. 58 217-227. https://doi.org/10.1016/ S0960-8524(96)00113-7

BARRERA-DÍAZ C, UREÑA-NUÑEZ F, CAMPOS E, PALOMARPARDAVÉ M and ROMERO-ROMO M (2003) A combined electrochemical-irradiation treatment of highly colored and polluted industrial wastewater. Radiat. Phys. Chem. 67 657-663. https://doi.org/10.1016/S0969-806X(02)00497-8

BENATTI CT and CELIA RG (2012) Fenton's process for the treatment of mixed waste chemicals. In: Organic Pollutants Ten Years after the Stockholm Convention - Environmental and Analytical Update. IntechOpen, Brazil.

BENITEZ-GARCIA J, JAUN LUIS A, FRANCISCO JR, JAVIER RUBIO F and ANA I (2001) The role of hydroxyl radicals for the decomposition of p-hydroxy phenylacetic acid in aqueous solutions. Water Res. 35 (5) 1338-1343. https://doi.org/10.1016/ S0043-1354(00)00364-X

BOUATAY F, BOUSSAID S, DRIRA N and MHENNI MED F (2015) Neutralization of textile wastewater using carbon dioxide. Int. J. Appl. Res. Text. 3 22-31.

CARINE A, MICHEL M, FRANÇOISE CH and FILIPPE M (2004) Coagulation-flocculation-decantation of dye house effluents: Concentrated effluents. J. Hazardous Mater. 116 57-64. https://doi. org/10.1016/j.jhazmat.2004.07.005

CARMEN Z and DANIELA S (2012) Textile organic dyes - characteristics, polluting effects and separation/elimination procedures from industrial effluents - a critical overview. In: Organic Pollutants Ten Years after the Stockholm Convention - Environmental and Analytical Update. IntechOpen, Brazil. https://doi.org/10.5772/32373

CIARDELLI G, CORSI L and MARCUCCI M (2000) Membrane separation for wastewater reuse in the textile industry. Resour. Conserv. Recycl. 31 189-197. https://doi.org/10.1016/S0921-3449(00)00079-3

ERTUGAY N and ACAR FNA (2017) Removal of COD and color from Direct Blue 71 azo dye wastewater by Fenton's oxidation: Kinetic study. Arab. J. Chem. 10 S1158-S1163.

ESLAMI A, MORADI M, GHANBARI F and FAYYAZ M (2013) Decolorization and COD removal from real textile wastewater by chemical and electrochemical Fenton processes: a comparative study. J. Environ. Health Sci. Eng. 11 31. https://doi.org/10.1186/2052-336X-11-31
GANESAN R and THANASEKARAN K (2011) Decolorization of textile dyeing wastewater by modified solar photo-Fenton oxidation. Int. J. Environ. Sci. 1 (6) 1168. https://doi.org/10.6088/ijes.00106020011

GHOREISHI S and HAGHIGHI R (2003) Chemical catalytic reaction and biological oxidation for treatment of non-biodegradable textile effluent. Chem. Eng. J. 95 163-169. https://doi.org/10.1016/ S1385-8947(03)00100-1.

GOTTLIEB A, SHAW CH, SMITH A, WHEATLEY A and FORSYTHE S (2003) The toxicity of textile reactive azo dyes after hydrolysis and decolorization. J. Biotechnol. 101 49-56. https://doi.org/10.1016/ S0168-1656(02)00302-4

HOSSEIN J, EDRIS B, AHMADREZA Y and MOSTAFA A (2014) Removal of azo dyes from aqueous solution using Fenton and modified Fenton processes. Health Scope. 3 (2) e15507. https://doi. org/10.17795/jhealthscope.15597

JAN P and LECH K (2002) Treatment of textile dyeing wastewater by hydrogen peroxide and ferrous ions. Fibres Text. East. Eur. 10 78-81.

KAHIA M (2017) The framework of Tunisian textile and clothing industry. Munich Personal RePEc Archive. URL: https://mpra. ub.uni-muenchen.de/60283.

KHATRI A, PEERZADA M, MOHSIN M and WHITE M (2015) A review on developments in dyeing cotton fabrics with reactive dyes for reducing effluent pollution. J. Clean. Prod. https://doi. org/10.1016/j.jclepro.2014.09.017

LEDAKOWICZ S, SOLECKA M and ZYLLA R (2001) Biodegradation, decolorization and detoxification of textile wastewater enhanced by advanced oxidation processes. J. Biotechnol. 89 175-184. https://doi. org/10.1016/S0168-1656(01)00296-6

MILED W, HAJ SAID A and ROUDESLI S (2010) Decolorization of high polluted textile wastewater by indirect electrochemical oxidation process. J. Text. Apparel, Technol. Manage. 6 1-6.

MILED W, SOULA S and LADHARI N (2015) Treatment of water soluble dyes in real textile wastewater by Fenton's process. Int. J. Sci. Res. Eng. Technol. 3 (2) 102-106.

MUHAMMAD AS, KHAN A and SAFIULLAH S (2012) Treatment of textile wastewater by coagulation precipitation method. J. Sci. Res. 4 623-633. https://doi.org/10.3329/jsr.v4i3.10777

NAWAZ MED S and AHSAN MED (2014) Comparison of physicochemical, advanced oxidation and biological techniques for the textile wastewater treatment. Alexandria Eng. J. 53 717-722. https:// doi.org/10.1016/j.aej.2014.06.007

PANGA KK, VIJAYA K, KAVITA V, POOJA K, BHAGAWAN D and VURIMINDI H (2018) Phycoremediation of sewage wastewater and industrial flue gases for biomass generation from microalgae. S. Afr. J. Chem. Eng. 25 133-146. https://doi.org/10.1016/j.sajce.2018.04.006

PERALTA-HERNÁNDEZ J, MEAS-VONG Y, FRANCISCO JR, THOMAS WCN, MANUEL I and LUIS AG (2008) Comparison of hydrogen peroxide-based processes for treating dye-containing wastewater: Decolorization and destruction of Orange II azo dye in dilute solution. Dyes Pigm. 76 656-662. https://doi.org/10.1016/j. dyepig.2007.01.001

PUGANESHWARY P, HAMIDI BIN AA and SHAIK F (2014) REVIEW: A review on the Fenton process for wastewater treatment. J. Innov. Eng. 2 (3) 4.

SAMANTA A and AGARWAL P (2009) Application of natural dyes on textiles. Indian J. Fibre Text. Res. 34 384-399.

SANGYONG K, CHULHWAN P, TAK-HYUM KM JL and SEUNGWOOK K (2003) COD reduction and decolorization of textile effluent using a combined process. J. Biosci. Bioeng. 95 102-105. https://doi.org/10.1016/S1389-1723(03)80156-1

SELÇUK H (2005) Decolorization and detoxification of textile wastewater by ozonation and coagulation processes. Dyes Pigm. 64 217-222. https://doi.org/10.1016/j.dyepig.2004.03.020

SIDDIQUA UMME H, ALI S, IQBAL M and HUSSAIN T (2017) Relationship between structure and dyeing properties of reactive dyes for cotton dyeing. J. Mol. Liq. 241 839-844. https://doi. org/10.1016/j.molliq.2017.04.057

SUN J-H, SHI S-H, LEE Y-F and SUN S P (2009) Fenton oxidative decolorization of the azo dye Direct Blue 15 in aqueous solution. Chem. Eng. J. 155 680-683. https://doi.org/10.1016/j.cej.2009.08.027 SUREYYA M, DENIZ K and TUGBA Ö-H (2004) Color and COD removal from wastewater containing Reactive Black 5 using Fenton's oxidation process. Chemosphere 54 435-441. 
https://doi.org/10.1016/j.chemosphere.2003.08.010

TOUNÉS A, TORNIKOSKI ET and GRIBAA F (2018) The formation of environmentally friendly intentions of sme owner-managers in an emerging country: The case of Tunisian's textile-clothing industry. Org. Environ. 1086026618764267.

WANG S (2008) A Comparative study of Fenton and Fenton-like reaction kinetics in decolorization of wastewater. Dyes Pigm. 76 714-720. https://doi.org/10.1016/j.dyepig.2007.01.012

WEN GUEY K (1992) Decolorizing dye wastewater with Fenton's reagent. WaterRes.26881-886.https://doi.org/10.1016/0043-1354(92)90192-7

XIAOYAN L, WEI W and PENG X (2010) Improving the wash fastness of direct dyes on cotton by $\mathrm{Si} / \mathrm{Ti}$ composite nanosol. Fibres Text.
East. Eur. 78 93-97.

YUSUF M (2018) Handbook of Textile Effluent Remediation ( $1^{\text {st }}$ edn). Pan Stanford, Romania. 434 pp.

ZAHARIA C, SUTEU D, MURESAN A, MURESAN R, POPESCU A (2009) Textile wastewater treatment by homogenous oxidation with hydrogen peroxide. Environ. Eng. Manage. J. 8 1359-1369.

ZAZOULI MED A, GHANBARI F, YOUSEFI $M$ and MADIHIBIDGOLI S (2017) Photocatalytic degradation of food dye by Fe3O4-TiO2 nanoparticles in presence of peroxymonosulfate: The effect of UV sources. J. Environ. Chem. Eng. 5 (3) 2459-2468. http:// dx.doi.org/doi:10.1016/j.jece.2017.04.037 